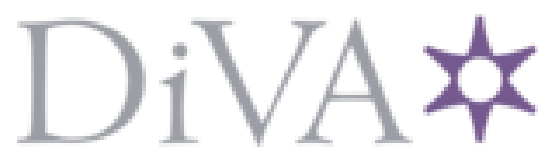

http://www.diva-portal.org

\title{
Preprint
}

This is the submitted version of a paper published in Evolution \& Development.

Citation for the original published paper (version of record):

Janssen, R., Eriksson, B., Budd, G., Akam, M., Prpic, N. (2010)

Gene expression patterns in an onychophoran reveal that regionalization predates limb segmentation in pan-arthropods.

Evolution \& Development, 12(4): 363-372

http://dx.doi.org/10.1111/j.1525-142X.2010.00423.x

Access to the published version may require subscription.

N.B. When citing this work, cite the original published paper.

Permanent link to this version:

http://urn.kb.se/resolve?urn=urn:nbn:se:uu:diva-135134 


\section{Gene expression patterns in an onychophoran reveal that regionalization predates limb segmentation in pan- arthropods}

Ralf Janssen ${ }^{1}()$, Bo Joakim Eriksson ${ }^{2,4}$, Graham E. Budd ${ }^{1}$, Michael Akam², Nikola- Michael Prpic $^{3}$

1 Department of Earth Sciences, Uppsala University, Villavägen 16, 75236 Uppsala, Sweden

2 Department of Zoology, University Museum of Zoology, Downing Street, Cambridge CB2 3EJ, UK

3 Georg-August-Universität, Johann-Friedrich-Blumenbach-Institut für Zoologie und Anthropologie, Abteilung Entwicklungsbiologie, GZMB, Ernst-Caspari-Haus, Justus-vonLiebig-Weg 11, 37077 Göttingen, Germany

4 Present address: School of Biological and Chemical Sciences, Queen Mary, University of London, Mile End Road, London E1 4NS, UK

(*) Author for correspondence:

Ralf Janssen

Department of Earth Sciences, Uppsala University, Villavägen 16, 75236 Uppsala, Sweden

Telephone: 0046184712763

FAX: 0046184712592

e-mail: ralf.janssen@geo.uu.se

Number of words: 6156 (in total)

Number of figures: 5

Running head: Appendage patterning in onychophorans 


\begin{abstract}
In arthropods, such as Drosophila melanogaster, the leg gap genes homothorax (hth), extradenticle (exd), dachshund (dac) and Distal-less (Dll) regionalize the legs in order to facilitate the subsequent segmentation of the legs. We have isolated homologs of all four leg gap genes from the onychophoran Euperipatoides kanangrensis and have studied their expression. We show that leg regionalization takes place in the legs of onychophorans even though they represent simple and nonsegmented appendages. This implies that leg regionalization evolved for a different function and was only later co-opted for a role in leg segmentation. We also show that the leg gap gene patterns in onychophorans (especially of $h t h$ and exd) are similar to the patterns in crustaceans and insects, suggesting that this is the plesiomorphic state in arthropods. The reversed hth and exd patterns in chelicerates and myriapods are therefore an apomorphy for this group, the Myriochelata, lending support to the Myriochelata and Tetraconata clades in arthropod phylogeny.
\end{abstract}




\section{Introduction}

The arthropods are the most speciose animal phylum comprising an estimated 10 million species in four large classes, the Chelicerata (e.g. spiders, scorpions), the Crustacea (e.g. crabs, shrimps), the Myriapoda (e.g. centipedes, millipedes) and the Insecta (e.g. flies, beetles). As their name suggests, arthropods are characterized by segmented (jointed) appendages, an evolutionary novelty (apomorphy). Closely related outgroups, the tardigrades (water bears) and onychophorans (velvet worms), do possess appendages, but these are not segmented. In onychophorans, the limbs are undivided with only an annulated ectoderm: in tardigrades the limbs are telescopic rather than articulated as in the arthropods. Such limbs are collectively, if somewhat inaccurately, referred to as "lobopods".

A substantial number of stem group arthropods from the fossil record are now available that provide some clues about limb evolution in basal arthropods. It is now broadly accepted from fossil taxa such as Pambdelurion and Megadictyon that an essentially lobopodous limb persisted up the stem group from a lobopodous last common ancestor (e.g. Budd 1996, 1998; Edgecombe 2010; but cf. Zhang and Briggs 2007 for a contrary view). The subsequent evolution of the arthropod limb is, however, considerably more controversial. At least one clade of stem group arthropods, the anomalocaridids, apparently lack walking limbs altogether; whilst their presence in other stem group forms such as Opabinia and Kerygmachela is disputed. These taxa, together with the anomalocaridids, possess lateral, gillbearing lobes (Budd 1996; Daley et al. 2009). The suggestion has thus been made that the walking legs of onychophorans were transformed into the lateral lobes, which later developed the walking limbs of arthropods. The implication would therefore be that onychophoran and 
arthropod walking limbs are not homologous as walking limbs (Zhang and Briggs 2007). Such a suggestion seems to be rendered unlikely by the presence of both lateral lobes and walking lopopodous limbs in Pambdelurion (Budd 1997); but the hypothesis of non-homology might also be weakened or strengthened by the study of gene expression in both arthropod and onychophoran limbs.

The genetic mechanisms that underlie arthropod leg segmentation have been studied in some detail in the fly Drosophila melanogaster. It has been shown that leg segmentation is controlled by a hierarchical gene network, that is reminiscent of the body segmentation cascade, but uses different genes (Rauskolb and Irvine 1999; Rauskolb 2001). The principal step is the subdivision (regionalization) of the legs into broad proximal, medial and distal domains by the expression of the leg gap genes homothorax (hth), extradenticle (exd), dachshund (dac) and Distal-less (Dll) (e.g. Abu-Shaar and Mann 1998). Their overlaps of expression subsequently serve as a kind of "address code" to define the location where the leg segmentation genes of the Notch pathway are activated in segmental rings and specify the location of the final leg joints (Rauskolb 2001; Bishop et al. 1999; de Celis et al. 1998). This leg segmentation mechanism is conserved in other arthropods as well and thus is the molecular basis of the character uniting all extant arthropods, segmented legs (Prpic and Damen 2009).

When did this leg regionalization mechanism evolve? To answer this question we have turned to the Onychophora, a close outgroup of the Arthropoda. We show here that the principal step of the leg segmentation gene cascade, the regionalization using $h t h, e x d, d a c$ and $D l l$ is already present in the legs of Euperipatoides kanangrensis, although the legs are simple tubes, without 
joints or morphological evidence for regionalization. We suggest that the regionalization mechanism using the leg gap genes has evolved for a purpose other than leg segmentation, but has then gained control over the Notch signaling pathway in the arthropod ancestor. This led to the origin of the segmented leg (arthropodium) as an important evolutionary novelty, because morphological subdivision of the legs possibly faciliated the individual leg segments to evolve into new shapes and functions. The presence of leg regionalization by the leg gap genes in onychophorans also allows to reconstruct the evolution of the spatial specificity of the leg gap genes in the arthropods. Expression data for these genes are available for several species from all four arthropod classes (e.g. Abzhanov and Kaufman 2000; Prpic et al. 2003; Prpic and Tautz 2003, reviewed also in Angelini and Kaufman 2005) and similarities in the expression of $D l l, d a c$, $h t h$, and exd during leg development subdivide the arthropods into two groups: insects and crustaceans on the one hand, and myriapods and chelicerates on the other hand. This subdivision agrees with other similarities in the development of the nervous and sensory system (Whitington and Bacon 1997; Dohle 2001, Dove and Stollewerk 2003; Kadner and Stollewerk 2004; Pioro and Stollewerk 2006), and with some recent molecular phylogenies (Hwang et al. 2001; Mallatt et al. 2004; Pisani et al. 2004; but see also Telford et al. 2007; Rota-Stabelli and Telford 2008), but the evolutionary significance of the observed similarities and differences in spatial and temporal gene expression is unclear, as the ancestral state is unknown. Our work on an onychophoran provides outgroup data for leg patterning in the arthropods and suggests that the similarities between leg patterning in myriapods and chelicerates are apomorphic and not plesiomorphic, thus supporting the taxon Myriochelata (myriapods and chelicerates) (Roeding et al. 2009). 


\section{Materials and Methods}

\section{Adult collection and embryo fixation}

Fertilized female specimens of Euperipatoides kanangrensis were collected in Kanangra Boyd National Park, NSW, Australia. Since E. kanangrensis is a viviparous species, the embryos had to be dissected out of the females. Prior to this procedure the females were dispatched in a killing jar charged with ethyl acetate. The ovaries of a single specimen contain embryos of various different stages (for a review see Walker and Tait (2004)). After removal of embryonic membranes the embryos were fixed in $4 \%$ formaldehyde in $0.1 \mathrm{M}$ phosphate buffer (pH 7.4) for four to six hours at room temperature. The embryos were then dehydrated in $100 \%$ methanol and stored at $-20^{\circ} \mathrm{C}$.

\section{Gene cloning and phylogenetic sequence analysis}

RNA isolation and cDNA synthesis were carried out as described for the pill millipede Glomeris marginata (Janssen et al. 2004). An initial Distal-less (Dll) fragment was amplified by using the primer sets described in Prpic and Tautz (2003). The primers used for dac were as described in Prpic et al. (2001). The primers used for $h t h$ and exd were as described in Prpic et al. (2003). Additional sequence information of $D l l$ was obtained by RACE (GeneRacer cDNA amplification Kit, Invitrogen). Sequences of the gene fragments were determined by means of Big Dye chemistry on an ABI3730XL analyser by a commercial sequencing service (Macrogen). The sequences are available from the EMBL nucleotide database under Accession Numbers FN257943 (Dll), FN257941 (dac), FN257944 ( $h t h$, isoform A), FN257945 ( $h t h$, isoform B) and FN257942 (exd). For the phylogenetic analysis the sequences 
were aligned using Clustal_X (Thompson et al. 1997) on the basis of the BLOSUM 62 residue comparison matrix (Henikoff and Henikoff 1992); gap introduction penalty of 1 and a gap extension penalty of 1. Maximum likelihood analysis was then carried out by using the Quartet Puzzling method (Strimmer and von Haeseler 1996) as implemented in PAUP 4.0b10 (Swofford 2002).

\section{In situ hybridization}

Single color whole-mount in situ hybridizations and double staining were performed essentially as described for the pill millipede Glomeris marginata (Janssen et al. 2008). Digoxigenin-labeled RNA probes for all genes were transcribed from the entire cloned fragments. For $h t h$ we used the long isoform (isoform A). Both protocols, the single staining as well as the double staining protocol, were optimized according to the needs of $E$. kanangrensis embryos; main changes include a change of the hybridization temperature from previously $65^{\circ} \mathrm{C}$ to now $60^{\circ} \mathrm{C}$; no protein-K treatment was performed; washing steps were prolonged. Detailed step-by-step protocols are available from the authors upon request.

\section{Results}

\section{Staging of onychophoran limbs}

Each embryo from late stage II on has a series of developing legs (up to 15 in stage-V embryos) of different developmental maturity (Walker and Tait 2004). Segments are added from a posterior growth zone and hence the more posterior legs are less developed than the 
ones of anterior segments in the same embryo. We distinguish a series of developmental stages of legs. Note that the stage of frontal appendage, jaw and oral papilla are defined by the stage of the embryo. Stage-1 leg: The bud of the leg appears as conical outgrowth (first seen in late stage- II embryos). Stage-2 leg: The leg elongates but is still conical (first seen in early stage-III embryos). Stage-3 leg: Annulation begins, but proper annuli have still not formed. The leg begins to curve towards ventral (first seen in very late stage-III embryos (not shown in Walker and Tait 2004)). Stage-4 leg: The first four annuli have formed (first seen in early stage-IV embryos). Stage-5 leg: Five annuli have formed (first seen in late stage-IV embryos). Stage-6 leg: Six annuli have formed (first seen in stage-V embryos). Stage-7 leg: Claws begin to form (first seen in early stage-VI embryos). Stage-8 leg: The distal claws have formed (first seen in late stage-VI embryos). In this paper expression patterns are shown in stage-2, stage-3 and stage-4 legs.

\section{Leg gap genes from Euperipatoides kanangrensis}

Phylogenetic analysis of the Dll fragment obtained from E. kanangrensis showed that it is most similar to the Dll gene from the mite Tetranychus urticae (Fig. 1A). The remaining chelicerate $D l l$ genes form a monophyletic group with the $D l l$ gene from the millipede Glomeris marginata (reliability value $=50$ ). The insect and crustacean $D l l$ genes form a separate group with high support (reliability value $=80)($ Fig. 1A). The phylogenetic analysis of the E. kanangrensis dac fragment places it in a group with the dac genes from crustaceans, myriapods and chelicerates, while the insect dac sequences form a separate group (Fig. 1B). We isolated two different cDNA fragments for the hth gene from E. kanangrensis. However, these differ only by an insertion within the longer form and otherwise are identical and we 
interpret these different forms as different splicing variants of the same gene product. The two isoforms group together in the phylogenetic analysis (Fig. 1C) and form a monophyletic group together with the hth genes from chelicerates. All exd genes from arthropods and E. kanangrensis are closely related as evidenced by the short tree edges (Fig. 1D). The fragment from E. kanangrensis is most similar to the exd gene from Glomeris marginata.

\section{Expression of Distal-less and dachshund}

The expression of the distal leg determinant $\mathrm{Dll}$ in an onychophoran has been studied previously using a cross-reacting anti-Dll antibody (Panganiban et al. 1997). We were interested in complementing these data with mRNA expression data and we have therefore studied the expression of $D l l$ in E. kanangrensis. As expected, $D l l$ is expressed in the distal portion of all appendages, including the frontal appendage ("antenna"), the jaw, and the oral papilla (Fig. 2A-E). In the locomotory legs expression of $D l l$ is initially very strong (Fig. 2D), but becomes restricted to a smaller number of distal cells later in development (Fig. 2E). This restriction of $\mathrm{Dll}$ to distalmost cells correlates with the emergence and expansion of dac expression. The expression of $d a c$ arises in the legs first in a ventral sector (Fig. 2I) within the Dll domain (Fig. 2L). Later, dac expression forms a complete ring around the legs (Fig. 2J) correlating with the dowregulation of $\mathrm{Dll}$ in this area (Fig. 2K). The dac gene is not expressed in the frontal appendage (Fig. 2F) and the jaw (Fig. 2G), whereas it is expressed in a thin ring in the oral papilla (Fig. 2H). Apart from the appendages, $D l l$ and $d a c$ are also expressed in other places. Next to the mouth opening and encasing the jaw appendage are the lip bulges that will form the lateral walls of the preoral cavity. There are three bulges on each side of the head and all three express $D l l$ in their tips (Fig. 2N), but only the anterior two also express $d a c$ 
in a small dot at their tips (Fig. 2M). Dll is also expressed in the developing ventral nervous system and in two small groups of dorsal cells in each segment (Fig. 2P). These two groups are located dorsal and dorsally anterior to the legs, respectively (arrows in Fig. 2P). The dac gene is also expressed in the central nervous system in the brain lobes (see asterisk in Fig. 2F) and in the developing ventral nerve cord (Fig. 2O).

\section{Expression of homothorax and extradenticle}

In the body expression of exd is largely ubiquitous (Fig. 3J). The expression is however clearly enhanced in the brain lobes, but the anterior rim appears to lack exd transcripts (Fig. $3 J)$. In the body hth is expressed in the anterior-ventral part of the head lobes, their posterior rims and ventral to the developing limbs (Fig. 3I and not shown). Ventral to the oral papilla (opp) and jaw exd forms a single block of expression; the ventral tissue between the legs is free from expression (Fig. 3I). Generally like exd also hth may be expressed at very low level in most tissues of the trunk. Our in situ hybridization technique cannot unambiguously separate such weak expression from possible background staining. In the appendages the genes are expressed in overlapping but different patterns, except for the frontal appendage. In the frontal appendage both genes are restricted to the basis of the limb (Fig. 3A, E). In the jaw (Fig. 3B, F), the oral papilla (Fig. 3C, G) and the locomotory legs (Fig. 3D, H), hth is restricted to the proximal half of the appendage and the distal half does not express hth, whereas exd is expressed ubiquitously in these appendage types, but the expression level is lowered near the distal end of the appendages. We have then compared the expression of $h t h$ and exd in young (stage-2) leg buds and older (stage-3) legs and also established their expression in relation to the medial leg marker $d a c$. We found that in stage-2 leg buds exd is 
already expressed ubiquitously with a lowered expression level at the tip (Fig. 4A), and hth expression is restricted to the area around the base of the leg buds (Fig. 4D). In stage-3 legs exd is still expressed ubiquitously and the lowered expression levels are still confined to the distal tip of the legs (Fig. 4B), while hth shows a clearcut border of expression in the middle of the legs: proximal cells express the gene and distal cells do not (Fig. 4E). This differential expression is also mirrored in the relation of $h t h$ and exd expression to the expression of $d a c$. The expression of exd completely overlaps with the dac expression stripe (Fig. 4C), but the expression of $h t h$ abuts the dac stripe with no overlap of the two genes (Fig. 4F).

\section{Discussion}

\section{Leg gap gene expression supports walking limb homology in arthropods and onychophorans}

Although it is normally assumed as a matter of course, the basis of the hypothesis of homology between the walking limbs of onychophorans and arthropods is rarely examined (see also Prpic (2008) for a hypothesis on appendage homology in arthropods, onychophorans, and annelids). Whilst the test for such a hypothesis must ultimately be phylogenetic, the initial hypothesis can be strengthened by the discovery of more features that unite the two structures. However, we show here that the developing legs of the onychophoran E. kanangrensis are fully regionalized by the leg gap genes in a fashion that is strikingly similar to leg regionalization in the arthropods, thus adding support to the hypothesis of homology. This is contrary to the implicit suggestion of Zhang and Briggs (2007), who present a tree in which 
walking limb loss characterises the arthropod stem group, as it is shared by the successive plesions represented by Opabinia and the anomalocaridids. In their scenario, the arthropod articulated limb is a de novo structure rather than being a direct modification of the onychophoran walking limb (cf. Olesen et al. 2001). Of equal interest would be the leg gap gene expression profile in the limbs of tardigrades, whose phylogenetic position continues to be problematic (e.g. Lartillot and Philippe 2007). However, the difficulties of working with tardigrades have as yet prevented these data being gathered.

\section{Leg regionalization by the leg gap genes precedes the origin of segmented arthropodia}

Regionalization by the leg gap genes precedes segmentation of the legs (e.g. Abu- Shaar and Mann 1998; Rauskolb and Irvine 1999; Rauskolb 2001). One might therefore expect that the unsegmented legs of onychophorans are not regionalized in the same way as in arthropods during development. The presence of arthropod-like leg regionalization in E. kanangrensis suggests that leg regionalization had evolved in the pan-arthropod ancestor for a purpose other than leg segmentation before it was later redeployed for a function in leg segmentation in the arthropods, and that it still serves this ancestral purpose in the developing legs of onychophorans. This evolution of a general regionalization mechanism, which is the precursor of a mechanism specifying the boundaries and identities of repetitive units, has a parallel in the evolution of the Hox body regionalization mechanism. The Hox mechanism serves to diversify the body segments in segmented animals (e.g. Lewis 1978; Damen et al. 1998; Schilling and Knight 2001; Deutsch and Mouchel-Vielh 2003; Janssen and Damen 2006; Kulakova et al. 2007), but is already present in unsegmented animals as well (e.g. Papillon et al. 2005; Orii et al. 1999; Hejnol and Martindale 2009). This strongly suggests that the body 
regionalization by the Hox genes evolved for a reason other than segment diversification (see also Chiori et al. 2009). The original function of the Hox regionalization mechanism might have been related to the positioning of organs or specific cell types along the body axis in unsegmented animals before it was redeployed for conferring positional information and identity to repetitive units in segmented animals. Similarly, we propose that the regionalization of the developing legs of Onychophora also serves the positioning of structures within the unsegmented leg. Unfortunately, functional studies are not yet possible in E. kanangrensis and thus the testing of this hypothesis has to be left to future investigations.

\section{Leg gap gene expression profiles support the Myriochelata and Tetraconata clades in arthropod phylogeny}

There are currently three hypotheses for the position of the Myriapoda in the arthropod phylogenetic tree: (1) The traditional Atelocerata hypothesis joins insects and myriapods and is supported by morphological data such as the presence of the limb-less intercalary segment, trachea, ectodermal malphigian tubules and a head composed of five segments (plus an ocular region) encased in a typical head capsule. The Atelocerata hypothesis is however challenged by the Tetraconata concept suggesting a sister-group, or even in-group relationship of insects and crustaceans (reviewed in Dohle (2001)). This theory is strongly supported by the majority of molecular studes (e.g. Regier et al. 2010). (2) The Mandibulata hypothesis regards the myriapods as the sister group to the Tetraconata. This hypothesis is supported by the possession of mandibles and the structure of the ommatidia (reviewed in Schminke (1996)). (3) The Myriochelata hypothesis joins the myriapods with the chelicerates to form the taxon Myriochelata (also called Paradoxopoda) as the sister group to the Tetraconata (Hwang et al. 
2001; Mallatt et al. 2004; Pisani et al. 2004). The grouping of myriapods and chelicerates is supported by similarities in the development of the nervous system (Dove and Stollewerk 2003; Kadner and Stollewerk 2004; Pioro and Stollewerk 2006) and the appendages (Prpic et al. 2003; Prpic and Damen 2004; Prpic and Tautz 2003). So far, however, the plesiomorphic state of these characters was not known, and thus it was not possible to establish their apomorphic nature. Recent results from the Onychophora, however, suggest that the specific features of nervous system development in the Myriapoda and Chelicerata are synapomorphic for these two groups, thus supporting the Myriochelata hypothesis (Mayer and Whitington 2009a; Mayer and Whitington 2009b, Harzsch 2004). We have here investigated leg patterning in an arthropod outgroup, the Onychophora. Features that the arthropods have in common with the onychophorans are likely to trace from a common ancestor and hence to be symplesiomorphies of the two groups. This outgroup comparison analysis thus allows us to establish the likely ancestral (plesiomorphic) state of appendage patterning in the arthropods. The combined expression of $h t h$ and $e x d$ is confined to the proximal area of the legs, and this is conserved in all arthropod groups (Prpic et al. 2003; Prpic and Tautz 2003; Prpic and Telford 2008), thus supporting the idea that co-expression of hth and exd generally determines proximal leg fate (Gonzalez-Crespo and Morata 1996). It has been noted previously that the distal patterns of hth and exd expression in insects and crustaceans (exd expressed throughout the distal leg and hth not expressed in the distal leg) are reversed in the legs of spiders and myriapods (Prpic et al. 2003; Prpic and Tautz 2003; Prpic and Telford 2008). In order to ensure proper specification of proximal fate, transformation of the expression patterns from one condition to the other either requires the simultaneous change of the regulation of both genes, or the passing through an intermediate stage in which both genes are confined to the 
proximal leg (see also Prpic et al. (2003)). Both cases represent complex events and therefore it appears unlikely that it has happened several times during evolution. As such the spatial specificity of exd and hth is a useful character for phylogenetic reconstruction provided the plesiomorphic and apomorphic states can be determined. Our data show that the condition in onychophorans is very similar to the condition in insects and crustaceans (Fig. 5A) suggesting that this is the plesiomorphic state in the arthropods (Fig. 5B). The reversal of the patterns in myriapods and chelicerates is then tentatively interpreted as a synapomorphy of the two groups supporting the Myriochelata as a monophyletic group (Fig. 5B). The expression profile of $d a c$ and $D l l$ is highly dynamic and changes during development (e.g. Abzhanov and Kaufman (2000), Prpic et al. (2001), Inoue et al. (2002), Prpic et al. (2003), Prpic and Tautz (2003), Angelini and Kaufman (2004), Prpic and Damen (2004), and Prpic and Telford (2008)). In insects and crustaceans the dac domain first appears within the Dll domain, whereas in spiders and myriapods the $d a c$ and $D l l$ domains appear separately, subsequently expand during leg growth, and overlap only later and only partially. The dac domain in onychophorans appears within the $D l l$ domain and thus in a fashion very similar to crustaceans and insects (Fig. 5). Consequently, the distinct dynamics of the dac and Dll expression profile in chelicerates and myriapods is again tentatively interpreted as a synapomorphy of these two groups (Fig. 5B). Nevertheless, it should be stressed that the strong majority of morphological data and recent molecular analyses support Mandibulata (e.g. Budd and Telford 2009; Edgecombe 2010; Regier et al., 2010); further investigation is clearly required to resolve the issue.

\section{Conclusions}


Gene expression data in onychophoran limbs provides out-group data against which character state changes in the arthropods can be polarised. The overall expression patterns and dynamics of Dll, dac, exd and hth resemble those of the insects and crustaceans rather than the myriapods and chelicerates. The implication is that the insect-crustacean pattern is plesiomorphic, whereas that of the chelicerates-myriapods is derived, thus counting as a character in support of a controversial chelicerate plus myriapod clade, Myriochelata. In addition to its phylogenetic implications, the data also suggest that limb regionalisation in the panarthropods preceded division into limb segments. The functional significance of this regionalisation is unclear, but might in the future be addressed by functional studies of the genes involved. In addition, both expression and functional studies of the same genes in tardigrades would add further depth to the data presently available.

\section{Acknowledgements}

This work has been supported by the Swedish Research Council (VR: grant to GEB), the European Union via the Marie Curie Training network "ZOONET" (MRTN-CT- 2004-005624 (to GEB and RJ)), and by the Deutsche Forschungsgemeinschaft (grant number PR 1109/1-1 to NMP). The authors wish to thank Noel Tait, Jean Joss and Rolf Ericsson for their help during collection of specimen.

\section{References}


Abu-Shaar, M., and Mann, R. S. 1998. Generation of multiple antagonistic domains along the proximodistal axis during Drosophila leg development. Development 125: 3821-3830.

Abzhanov, A., and Kaufman, T. C. 2000. Homologs of Drosophila appendage genes in the patterning of arthropod limbs. Dev. Biol. 227: 683-689.

Angelini, D. R., and Kaufman, T. C. 2004. Functional analyses in the hemipteran Oncopeltus fasciatus reveal conserved and derived aspects of appendage patterning in insects. Dev. Biol. 271: 306-321.

Angelini, D. R. and Kaufman, T. C. 2005. Insect appendages and comparative ontogenesis. Dev. Biol. 286: 57-77.

Bishop, S. A., Klein, T., Martinez Arias, A., and Couso, J.P. 1999. Composite signalling from Serrate and Delta establishes leg segments in Drosophila through Notch. Development 126: 2993-3003.

Budd, G. E. 1996. The morphology of Opabinia regalis and the reconstruction of the arthropod stem-group. Lethaia 29: 1-14.

Budd, G. E. 1997. Stem-group arthropods from the Lower Cambrian Sirius Passet fauna of North Greenland. Systematics Association Special Volume 55: 125-138. 
Budd, G.E. and Telford, M.J. 2009. The origin and evolution of arthropods. Nature 457, 812817.

Chiori, R., Jager, M., Denker, E., Wincker, P., Da Silva, C., Le Guyader, H., Manuel, M., and Queinnec, E. 2009. Are Hox genes ancestrally involved in axial patterning? Evidence from the hydrozoan Clytia hemisphaerica (Cnidaria). PLoS ONE 4: e4231.

Daley, A. C., Budd, G. E., Caron, J.-B., Edgecombe, G. D. and Collins, D. 2009. The Burgess Shale anomalocaridid Hurdia and its significance for early euarthropod evolution. Science 323: $1597-1600$.

Damen, W. G. M., Hausdorf, M., Seyfarth, E-A., and Tautz, D. 1998. A conserved mode of head segmentation in arthropods revealed by the expression pattern of Hox genes in a spider. Proc Natl Acad Sci USA 95: 10665-10670.

de Celis, J.F., Tyler, D.M., de Celis, J., and Bray, S.J. 1998. Notch signalling mediates segmentation of the Drosophila leg. Development 125: 4617-4626.

Deutsch, J. S., and Mouchel-Vielh, E. 2003. Hox genes and the crustacean body plan. Bioessays 25: 878-887. 
Dohle, W. 2001. Are the insects terrestrial crustaceans? A discussion of some new facts and arguments and the proposal of the proper name "Tetraconata" for the monophyletic unit Crustacea + Hexapoda. Ann. Soc. Entomol. Fr. (N. S.) 37: 85-103.

Dove, H., and Stollewerk, A. 2003. Comparative analysis of neurogenesis in the myriapod Glomeris marginata (Diplopoda) suggests more similarities to chelicerates than to insects. Development 130: 2161-2171.

Edgecombe, D.G. 2010. Arthropod phylogeny: an overview from the perspectives of morphology, molecular data and the fossil record. Arthropod Structure and Development 39: 74-87.

Gonzalez-Crespo, S., and Morata, G. 1996. Genetic evidence for the subdivision of the arthropod limb into coxopodite and telopodite. Development 122: 3921-3928.

Harzsch, S. 2004. Phylogenetic comparison of serotonin-immunoreactive neurons in representatives of the Chilopoda, Diplopoda, and Chelicerata: Implications for arthropod relationships. J. Morphol. 259: 198-213.

Hejnol, A., and Martindale, M.Q. 2009. Coordinated spatial and temporal expression of Hox genes during embryogenesis in the acoel Convolutriloba longifissura. BMC Biol. 7:65 doi:10.1186/1741-7007-7-65. 
Henikoff, S., and Henikoff, J. G. 1992. Amino acid substitution matrices from protein blocks. Proc. Natl. Acad. Sci. USA 89: 10915-10919.

Hwang, U.W., Friedrich, M., Tautz, D., Park, C.J., and Kim, W. 2001. Mitochondrial protein phylogeny joins myriapods with chelicerates. Nature 413: 154-157.

Inoue, Y., Mito, T., Miyawaki, K., Matsushima, K., Shinmyo, Y., Heanue, T. A., Mardon, G., Ohuchi, H., and Noji, S. 2002. Correlation of expression patterns of homothorax, dachshund, and Distal-less with the proximodistal segmentation of the cricket leg bud. Mech. Dev. 113: 141-148.

Janssen, R., Prpic, N. M., and Damen, W. G. M. 2004. Gene expression suggests decoupled dorsal and ventral segmentation in the millipede Glomeris marginata (Myriapoda: Diplopoda). Dev. Biol. 268: 89-104.

Janssen, R., and Damen, W. G. M., 2006. The ten Hox genes of the millipede Glomeris marginata. Dev. Genes. Evol. 216: 451-465.

Janssen, R., Budd, G. E., Damen, W. G. M., and Prpic, N. M. 2008. Evidence for Wgindependent tergite boundary formation in the millipede Glomeris marginata. Dev. Genes Evol. 218: 361-370. 
Kadner, D., and Stollewerk, A. 2004. Neurogenesis in the chilopod Lithobius forficatus suggests more similarities to chelicerates than to insects. Dev. Genes Evol. 214: 367-379.

Kulakova, M., Bakalenko, N., Novikova, E., Cook, C. E., Eliseeva, E., Steinmetz, P. R., Kostyuchenko, R. P., Dondua, A., Arendt, D., Akam, M., and Andreeva, T. 2007. Hox gene expression in larval development of the polychaetes Nereis virens and Platynereis dumerilii (Annelida, Lophotrochozoa). Dev Genes Evol. 217: 39-54.

Lartillot, N. and Philippe, H. 2007. Improvement of molecular phylogenetic inference and the phylogeny of Bilateria. Philosophical Transactions of the Royal Society of London B 363: 1463-1472.

Lewis, E. B. 1978. A gene complex controlling segmentation in Drosophila, Nature 276: 565570.

Mallatt, J. M., Garey, J. R., and Shultz J. W. 2004. Ecdysozoan phylogeny and Bayesian inference: first use of nearly complete $28 \mathrm{~S}$ and $18 \mathrm{~S}$ rRNA gene sequences to classify the arthropods and their kin. Mol. Phylogenet. Evol. 31: 178-191.

Mayer, G., and Whitington, P. M. 2009a. Velvet worm development links myriapods with chelicerates. Proc. R. Soc. B 276: 3571-3579. 
Mayer, G., and Whitington, P. M. 2009b. Neural development in Onychophora (velvet worms) suggests a step-wise evolution of segmentation in the nervous system of Panarthropoda. Dev. Biol. 335: 263-275.

Olesen, J., Richter, S., and Scholtz, G. 2001. The evolutionary transformation of phyllopodous to stenopodous limbs in the Branchiopoda (Crustacea) - Is there a common mechanism for early limb development in arthropods. In. J. Dev. Biol. 45: 869-876.

Orii, H., Kato, K., Umesono, Y., Sakurai, T., Agata, K., and Watanabe, K. 1999. The planarian HOM/HOX homeobox genes (Plox) expressed along the anteroposterior axis. Dev. Biol. 210: 456-468.

Panganiban, G., Irvine, S. M., Lowe, C., Roehl, H., Corley, L. S., Sherbon, B., Grenier, J. K., Fallon, J. F., Kimble, J., Walker, M., Wray, G. A., Swalla, B. J., Martindale, M. Q., and Carroll, S. B. 1997. The origin and evolution of animal appendages. Proc. Natl. Acad. Sci. USA 94: 5162-5166.

Papillon, D., Perez, Y., Fasano, L., Le Parco, Y., and Caubit, X. 2005. Restricted expression of a median Hox gene in the central nervous system of chaetognaths. Dev. Genes Evol. 215: 369373. 
Pioro, H. L., and Stollewerk, A. 2006. The expression pattern of genes involved in early neurogenesis suggests distinct and conserved functions in the diplopod Glomeris marginata. Dev. Genes Evol. 216: 417-430.

Pisani, D., Poling, L. L., Lyons-Weiler, M., and Hedges, S. B. 2004. The colonization of land by animals: molecular phylogeny and divergence times among arthropods. BMC Biol. 2: 1 .

Prpic, N. M., Wigand, B., Damen, W. G. M., and Klingler, M. 2001. Expression of dachshund in wild-type and Distal-less mutant Tribolium corroborates serial homologies in insect appendages. Dev. Genes Evol. 211: 467-477.

Prpic, N. M., Janssen, R., Wigand, B., Klingler, M., and Damen, W. G. M. 2003. Gene expression in spider appendages reveals reversal of exd/hth spatial specificity, altered leg gap gene dynamics, and suggests divergent distal morphogen signaling. Dev. Biol. 264: 119-140.

Prpic, N. M., and Tautz, D. 2003. The expression of the proximodistal axis patterning genes Distal-less and dachshund in the appendages of Glomeris marginata (Myriapoda: Diplopoda) suggests a special role of these genes in patterning the head appendages. Dev. Biol. 260: 97112.

Prpic, N.M., and Damen, W.G. M. 2004. Expression patterns of leg genes in the mouthparts of the spider Cupiennius salei (Chelicerata: Arachnida). Dev. Genes Evol. 214: 296-302. 
Prpic, N. M. 2008. Parasegmental appendage allocation in annelids and arthropods and the homology of parapodia and arthropodia. Front. Zool. 5:17 doi:10.1186/1742- 9994-5-17.

Prpic, N. M., and Telford, M. J. 2008. Expression of homothorax and extradenticle mRNA in the legs of the crustacean Parhyale hawaiensis: evidence for a reversal of gene expression regulation in the pancrustacean lineage. Dev. Genes Evol. 218: 333- 339.

Prpic, N. M., and Damen, W. G. M. 2009. Notch-mediated segmentation of the appendages is a molecular phylotypic trait of the arthropods. Dev. Biol. 326: 262- 271.

Rauskolb, C., and Irvine, K. D. 1999. Notch-mediated segmentation and growth control of the Drosophila leg. Dev. Biol. 210: 339-350.

Rauskolb, C. 2001. The establishment of segmentation in the Drosophila leg. Development 128: $4511-4521$.

Regier, J.C., Shultz, J.W., Zwick, A., Hussey, A., Ball, B., Wetzer, R., Martin, J.W., and Cunningham, C.W. 2010. Arthropod relationships revealed by phylogenomic analysis of nuclear protein-coding sequences. Nature 463: 1079-1083.

Roeding, F., Borner, J., Kube, M., Klages, S., Reinhardt, R., and Burmester, T. 2009. A 454 sequencing approach for large scale phylogenomic analysis of the common emperor scorpion (Pandinus imperator). Mol. Phylogenet. Evol. 53: 826-834. 
Rota-Stabelli, O. and Telford, M. J. 2008. A multi criterion approach for the selection of optimal outgroups in phylogeny: Recovering some support for Mandibulata over Myriochelata using mitogenomics. Mol. Phylogenet. Evol. 48: 103-111.

Schilling, T. F., and Knight, R. D. 2001. Origins of anteroposterior patterning and Hox gene regulation during chordate evolution. Philos. Trans. R. Soc. Lond. B Biol. Sci. 356: 1599-613.

Schminke, H. K. 1996. Mandibulata. In: Westheide, W., and Rieger, R. (Eds.) Spezielle Zoologie, Teil 1: Einzeller und Wirbellose Tiere. Gustav Fischer Verlag, Stuttgart. Pp. 498500.

Strimmer, K., and von Haeseler, A. 1996. Quartet puzzling: a quartet maximum likelihood method for reconstructing tree topologies. Mol. Biol. Evol. 13: 964-969.

Swofford, D. L. 2002. PAUP. Phylogenetic Analysis Using Parsimony (*and Other Methods). Version 4. Sinauer Associates, Sunderland, MA.

Telford, M. J., Bourlat, S. J., Economou, A., Papillon, D. and Rota-Stabelli, O. 2007. The evolution of the Ecdysozoa. Philos. Trans.R. Soc. Lond. B 363: 1529-1537. 
Thompson, J. D., Gibson, T. J., Plewniak, F., Jeanmougin, F., and Higgins, D. G. 1997. The CLUSTAL_X windows interface: flexible strategies for multiple sequence alignment aided by quality analysis tools. Nucleic Acids Res. 25: 4876-4882.

Walker, M. H., and Tait, N. N. 2004. Studies of embryonic development and the reproductive cycle in ovoviviparous Australian Onychophora (Peripatopsidae). J. Zool. 264: 333-354.

Whitington, P. M., and Bacon, J. P. 1997. The organization and development of the arthropod ventral nerve cord: insights into arthropod relationships. In: Fortey, R. A., and Thomas, R. H. (Eds.) Arthropod Relationships. Chapman \& Hall, London. Pp 349-367.

Zhang, X.-1. and Briggs, D. E. G. 2007. The nature and significance of the appendages of Opabinia from the Middle Cambrian Burgess Shale. Lethaia 40: 161- 173. 


\section{Figure legends}

Figure 1. Phylogenetic analysis of the inferred protein sequences of the recovered gene fragments of (A) Dll, (B) dac, (C) hth, and (D) exd from E. kanangrensis with related genes from diverse arthropods. Each tree represents the unrooted majority rule consensus computed from 1000 intermediate trees produced with the quartet puzzling method (Strimmer and von Haeseler 1996). The numbers at the tree edges indicate the reliability values.

Figure 2. Expression of $D l l$ and dac in E. kanangrensis embryos. (A-E) Expression of Dll in the different appendage types. (A) Frontal appendage of stage-IV embryo. (B) Jaw of early stage-IV embryo. (C) Oral papilla of late stage-IV embryo. (D, E) Stage-3 and stage-4 leg respectively. (F-J) Expression of $d a c$ in the different appendage types. (F) Frontal appendage of stage-IV embryo. The asterisk denotes dac expression in the brain lobe. (G) Jaw of stage-IV embryo. (H) Oral papilla of stage-IV embryo. (I, J) Stage-3 and stage-4 leg respectively. (K, L) Double-staining of dac (red) and Dll (blue) in a late (K) and a early stage-3 leg (L). Note the appearance of the ventral $d a c$ expression within the $D l l$ expression domain (L) and the subsequent loss of $D l l$ expression where $d a c$ is expressed $(\mathrm{K}) .(\mathrm{M}, \mathrm{N})$ Expression of $d a c(\mathrm{M})$ and $\mathrm{Dll}(\mathrm{N})$ in the three lip bulges surrounding the jaw in stage-IV embryos. Expression domains in the lip bulges is denoted by arrows, absence of dac expression in the posterior bulge is denoted by the arrowhead. $(\mathrm{O}, \mathrm{P})$ Additional expression domains of $d a c(\mathrm{O})$ and $D l l$ (P). (O) $d a c$ is expressed in the ventral nervous system (arrows). (P) Dll is expressed in tissue ventral to the limb buds (arrowhead) and in two dots dorsal to the limb buds (arrows). Anterior 
is up in panels $\mathrm{M}-\mathrm{P}, \mathrm{M}$ and $\mathrm{N}$ are ventral, $\mathrm{O}$ and $\mathrm{P}$ lateral aspects (with ventral to the left). Abbreviations: fap, frontal appendage; opp, oral papilla.

Figure 3. Expression of hth and exd in E. kanangrensis embryos. (A-D) Expression of $h$ th in the different appendage types in stage-IV embryos. (A) Frontal appendage. (B) Jaw. (C) Oral papilla. (D) Stage-4 leg. (E-H) Expression of exd in the different appendage types. (E) Frontal appendage. (F) Jaw. (G) Oral papilla. (H) Stage-4 leg. The arrow points to weaker expression towards the leg tip. (I-J) Lateral views of whole-mount embryos stained for $h$ th expression (I) and exd expression (J). (I) hth is strongly expressed in tissue ventral to the limbs (arrowhead and arrows) and at the posterior rim of the brain lobe (thin arrow); the anterior and dorsal parts of the brain lobe do not express hth (asterisk). Abbreviations: fap, frontal appendage; blb, brain lobe; opp, oral papilla.

Figure 4. Comparison of the spatial specificity of exd and hth expression. (A, B) Expression of exd in a stage-2 (A) and an older stage-3 leg (B). (C) Co-expression of exd (blue) and dac (red) in a stage-3 leg. Note that the dac domain is fully included in the exd domain. (D, E) Expression of $h$ th in a stage-2 leg (D) and a stage-3 leg (E). Note that hth expression is restricted to the proximal leg part. (F) Co-expression of hth (blue) and dac (red) in an older leg. Note that the dac and hth domains do not overlap and form a sharp border between them.

Figure 5. Apomorphic and plesiomorphic features of appendage patterning in Onychophora and Arthropoda. (A) A schematic overview of the expression profiles of the leg gap genes exd (blue), hth (orange), dac (green), and Dll (red). Light shades of each color indicate weak 
expression or downregulation of expression during development. The exd gene is expressed throughout the legs in Onychophora, Crustacea, and Insecta, whereas it is restricted to proximal leg parts in Chelicerata and Myriapoda. The distal exd ring (asterisk) in spider appendages is not related to leg regionalization, but is regulated downstream of the Notch signaling pathway and is thus involved in leg segmentation (Prpic and Damen 2009). The $h t h$ gene is restricted to proximal leg parts in Onychophora, Crustacea, and Insecta, whereas it is also expressed in the distal leg in Chelicerata and Myriapoda. The dac domain is included in the $D l l$ domain from the time of its first appearance in Onychophora, Crustacea, and Insecta, whereas both genes are first expressed in non-overlapping domains (overlaping later during development) in Chelicerata and Myriapoda. (B) The spatial specificity of $h t h$ and exd and the first appearance of the dac domain within the Dll domain as seen in leg development of Onychophora, Crustacea, and Insecta are here interpreted as the plesiomorphic state in the pan-arthropods (red box "1"). The reversed spatial specificity of exd and hth and the Dll and dac domains that appear separately and overlap only later in leg development as seen in Chelicerata and Myriapoda are then interpreted as synapomorphies of the Chelicerata and Myriapoda (red box "2"). The schematic representations of arthropod gene expression in (A) are based on Abu-Shaar and Mann (1998), Abzhanov and Kaufman (2000), Prpic et al. (2001), Inoue et al. (2002), Prpic et al. (2003), Prpic and Tautz (2003), Angelini and Kaufman (2004), Prpic and Damen (2004), and Prpic and Telford (2008). 